\title{
M-81, A NEW PEPTIDE ANTIBIOTIC PRODUCED BY STREPTOMYCES GRISEUS SUBSP. PSYCHROPHILUS AT MODERATE TEMPERATURE
}

\author{
Noboru Yoshida, Shunil Hayashi, Yoshiki Tani and Koichi Ogata \\ Department of Agricultural Chemistry, Kyoto University \\ Sakyo-ku, Kyoto, Japan
}

(Received for publication October 16, 1972)

\begin{abstract}
M-81, a new water-soluble basic peptide antibiotic, was isolated from the culture filtrate of Streptomyces griseus subsp. psychrophilus AKU 2881, which produces cryomycin only at low temperatures. M- 81 was produced at $20 \sim 37^{\circ} \mathrm{C}$, but not below $20^{\circ} \mathrm{C}$. M- 81 was active against some Gram-positive bacteria. Its antimicrobial spectrum is more limited than those of cryomycin. It darkens at $208^{\circ} \sim 213^{\circ} \mathrm{C}$ with decomposition. The $\mathrm{LD}_{50}$ in mice by intraperitoneal injection is more than $300 \mathrm{mg} / \mathrm{kg}$.
\end{abstract}

Streptomyces griseus subsp. psychrophilus AKU 2881 is a psychrophilic actinomycete which produces a new peptide antibiotic, cryomycin, only at low temperatures. As described in preceding papers ${ }^{1,2)}$, cryomycin is produced between $0^{\circ} \mathrm{C}$ and $18^{\circ} \mathrm{C}$, but not above $20^{\circ} \mathrm{C}$, and possesses high activity against Bacillus subtilis IFO 3037.

Further investigations have revealed that at moderate temperatures Streptomyces griseus subsp. psychrophilus AKU 2881 produces another antibacterial substance inactive against $B$. subtilis. This active principle was isolated, characterized as a water-soluble basic substance with a high activity against Serratia polymuthicum IFO 3055 and Micrococcus lysodeikticus IFO 3333, and named M-81. The temperature range for $\mathrm{M}-81$ production is $20 \sim 37^{\circ} \mathrm{C}$. It is not produced below $20^{\circ} \mathrm{C}$. Its antimicrobial spectrum is narrower than that of cryomycin.

In this paper, the production, isolation and characterization of M-81 as well as its biological properties are described and compared with those of cryomycin.

\section{Production of Antibiotic M-81}

As shown in Fig. 1, Streptomyces griseus subsp. psychrophilus AKU 2881 produces two different antibiotics, cryomycin and M-81, respectively, at low and moderate temperatures. The two substances exhibit different $\mathrm{Rf}$ values on bioautography using butanol-acetic acidpyridine - water $(15: 3: 10: 12)$ as the developing solvent and Micrococcus lysodeikticus IFO 3333 as the test organism. S. griseus subsp. psychrophilus grows readily on a medium of

Fig. 1. Effect of incubation temperature on growth and antibiotic formation of Streptomyces griseus subsp. psychrophilus.

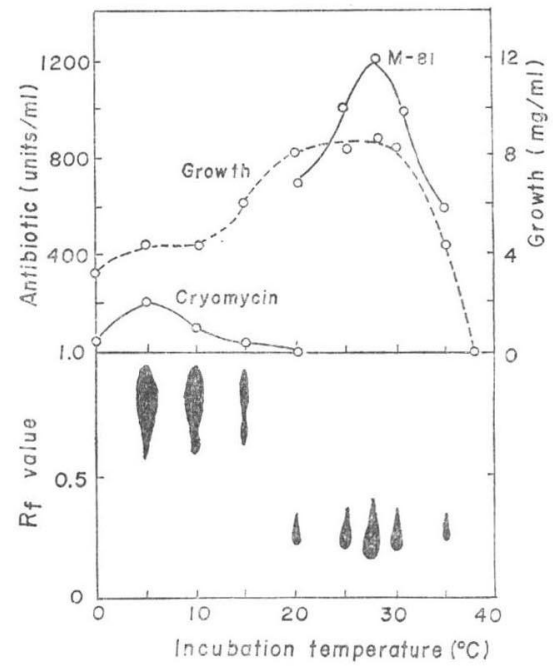


the following composition: Peptone $5 \mathrm{~g}$; soluble starch $20 \mathrm{~g} ; \mathrm{K}_{2} \mathrm{HPO}_{4} 2 \mathrm{~g} ; \mathrm{MgSO}_{4} \cdot 7 \mathrm{H}_{2} \mathrm{O} 1 \mathrm{~g}$; $\mathrm{FeSO}_{4} \cdot 7 \mathrm{H}_{2} \mathrm{O} 0.02 \mathrm{~g}$ in $1,000 \mathrm{ml}$ of tap water; at $\mathrm{pH} 6.5$ before sterilization. The maximum yield of the antibiotic was attained after $48 \sim 72$ hours. The yield of the antibiotic was markedly reduced when the organism was cultivated in a soybean-glycerol medium, which was the most suitable for the production of cryomycin.

\section{Isolation and Purification}

M-81 is found in the culture broth, but not in the mycelia. The isolation procedure is as follows: The culture broth was freed from mycelia and mixed with $1 \%(\mathrm{w} / \mathrm{v})$ active carbon. The carbon was harvested, washed and eluted with $28 \%$ aqueous ammonia-water-acetone $(5: 45: 50)$. The eluate was evaporated in vacuo to remove volatile matters, then it was passed through Dowex $1 \times 1\left(\mathrm{HCOO}^{-}\right)$and Dowex $1 \times 2\left(\mathrm{Cl}^{-}\right)$to remove most of the pigments and impurities. The active effluent was adsorbed on Amberlite $\mathrm{CG}-50\left(\mathrm{H}^{+}\right)$, followed by elution with $1 \mathrm{~N} \mathrm{HCl}-80 \%$ methanol (1:50). After being neutralized with Amberlite CG 4B $\left(\mathrm{OH}^{-}\right)$, the active eluate was condensed to a small volume and subjected to cellulose column chromatography using aqueous methanol of increasing concentration as the eluent. The active eluate was adsorbed on charcoal, followed by elution with $80 \%$ methanol.

Fig. 2. Ultraviolet absorption spectrum of antibiotic M-81.

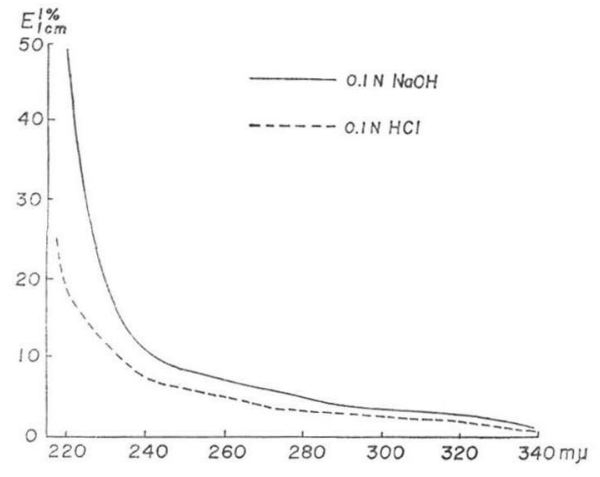

M-81 was obtained as a pale yellow powder by concentrating the eluate in vacuo and lyophilizing it from the aqueous solution.

\section{Physical and Chemical Properties}

M-81 is an antibiotic powder with weakly basic properties. It darkens at $208^{\circ} \sim 213^{\circ} \mathrm{C}$ with decomposition. Figure 2 shows its ultraviolet absorption spectrum in water. No maxima were observed down to $210 \mathrm{~m} \mu$. Figure 3 shows the infrared absorption spectrum using a $\mathrm{KBr}$ tablet of the desolvated powder of M-81. Elementary analysis gave

Fig. 3. Infrared absorption spectrum of antibiotic M-81 (in $\mathrm{KBr}$ ).

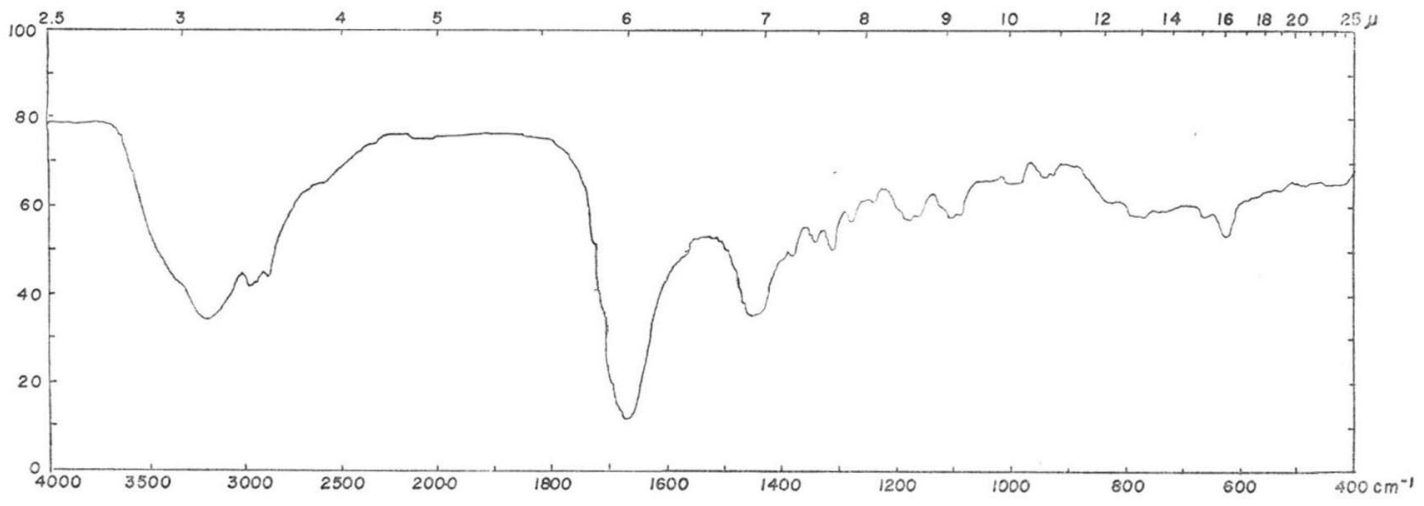


Table 1. Behavior of M-81 towards different chemical tests.

\begin{tabular}{|c|c|}
\hline Chemical test & Result \\
\hline Ninhydrin & positive \\
\hline $\mathrm{FeCl}_{3}$ & negative \\
\hline Alkaline $\mathrm{KMnO}_{4}$ & reduction when cold \\
\hline Acidic $\mathrm{KMnO}_{4}$ & reduction when cold \\
\hline Biuret & positive \\
\hline Xanthoprotein & positive \\
\hline MILLON & positive \\
\hline SAKAGUCHI & positive \\
\hline AdAM-KIEWICZ & positive \\
\hline PAuli & positive \\
\hline LIEBERMANN & negative \\
\hline TOLLENS & negative \\
\hline Dilute $\mathrm{I}_{2}$ solution & decolorization in cooling \\
\hline Anthrone & negative \\
\hline BENEDICT & negative \\
\hline
\end{tabular}

Fig. 6. Ion-exchange chromatography of antibiotic M-81 hydrolyzate.

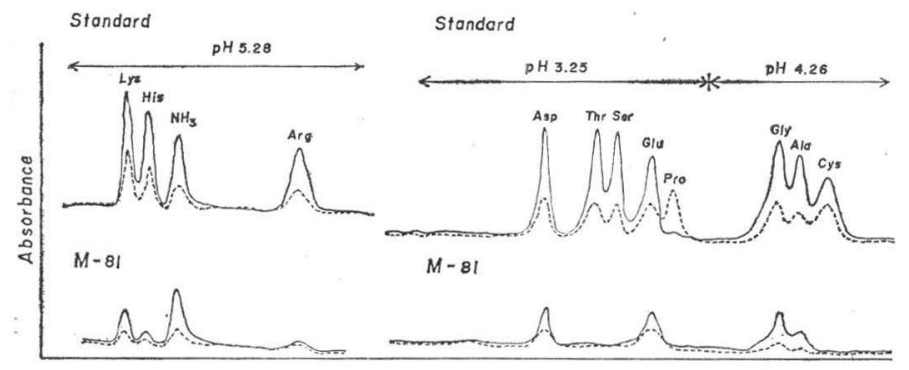

Fig. 4. Salt-out paper chromatogram of M-81,

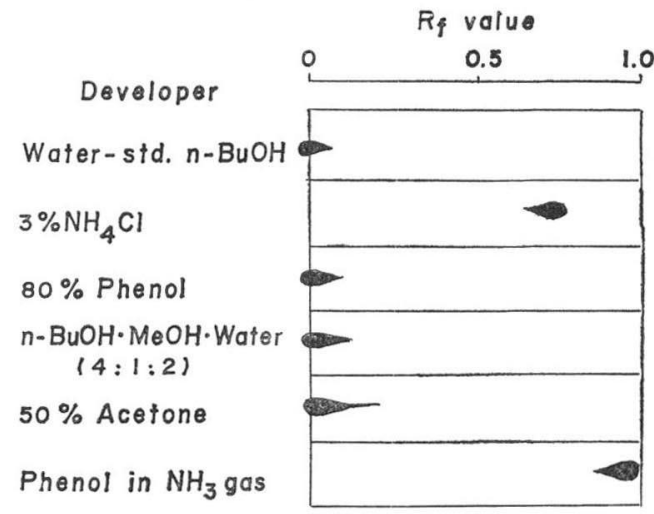

Fig. 5. Paper electrophoresis of cryomycin and M-81.

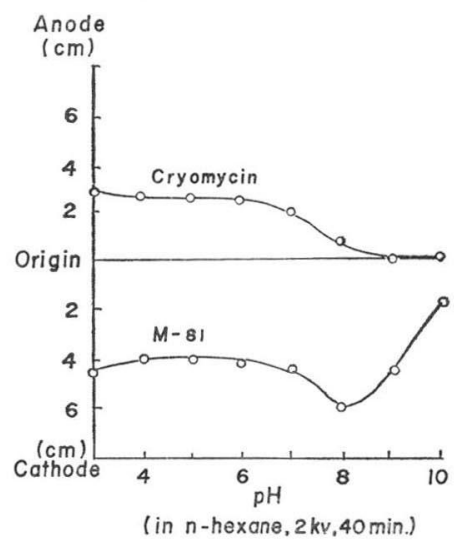

the following composition: C 45.52, H 9.05, N 13.10.

M-81 is soluble in water, methanol and ethanol, but insoluble in other organic solvents. The chemical reactions of $\mathrm{M}-81$ are given in Table 1. When M-81 was examined by paper chromatography using many solvent systems, a single active spot against Serratia polymuthicum IFO 3055 was observed (Fig. 4).

On paper electrophoresis at $15 \sim 20 \mathrm{~mA}$ and 2,000 volts for 40 minutes in each of several buffers $^{2)}$, M-81 moved toward the cathode, whereas cryomycin moved toward the anode (Fig. 5).

The nitrogen content, ninhydrin reaction and the infrared absorption spectrum indicated that $\mathrm{M}-81$ is a peptide antibiotic. As a result of analyzing the hydrolyzate of $\mathrm{M}-81$ with an automatic amino acid analyzer, lysine, histidine, arginine, aspartic acid, glutamic acid, glycine and alanine were detected (Fig. 6). The optical configulation of these amino acids and their sequence have not yet been determined. No fatty acids were detected in the hydrolyzate.

\section{Biological Properties}

The antimicrobial spectrum of M-81 obtained by the agar dilution streak method is shown 
Table 2. Antimicrobial spectrum of $\mathrm{M}-81$

\begin{tabular}{|c|c|c|c|}
\hline Microorganism & $\begin{array}{l}\text { M.I.C. } \\
(\mathrm{mcg} / \mathrm{ml})\end{array}$ & Microorganism & $\begin{array}{l}\text { M.I.C. } \\
(\mathrm{mcg} / \mathrm{ml})\end{array}$ \\
\hline Escherichia coli IFO 3208 & $>100$ & Streptomyces rimosus IFO 3226 & 6.3 \\
\hline Aerobacter aerogenes IFO 3320 & $>100$ & Saccharomyces cerevisiae AKU* 4100 & $>100$ \\
\hline Serratia polymuthicum IFO 3055 & 1 & Endomyces hordei IFO 0104 & 3.1 \\
\hline Proteus vulgaris IFO 3045 & $>100$ & Eremascus fertilis IFO 0691 & $>100$ \\
\hline Alcaligenes faecalis IFO 3160 & 12.5 & Schizosaccharomyces pombe IFO 0346 & $>100$ \\
\hline Flavobacterium arborescens IAM 1130 & 0.8 & Pichia polymorpha IFO 0195 & $>100$ \\
\hline Bacillus subtilis IFO 3037 & $>100$ & Hansenula anomala IFO 0118 & $>100$ \\
\hline Micrococcus lysodeikticus IFO 3333 & 0.8 & Saccharomycodes ıudwigii IFO 0339 & 50 \\
\hline Staphylococcus aureus IFO 3061 & $>100$ & Lipomyces lipoferus IFO 0673 & $>100$ \\
\hline Sarcina lutea IFO 3064 & 25 & Sporobolomyces salmonicolor IFO 0374 & $>100$ \\
\hline Corynebacterium equi IAM 1034 & 25 & Candida albicans IFO 0197 & $>100$ \\
\hline Arthrobacter simplex IFO 3530 & 25 & Trigonopsis variabilis IFO 0671 & 3.1 \\
\hline Brevibacterium ammoniagenes IFO 12071 & 50 & Torula rubra AKU 4730 & $>100$ \\
\hline Bacterium cadaveris IFO 3731 & $>100$ & Trichosporon cutaneum IFO 0174 & $>100$ \\
\hline Pseudomonas aeruginosa IFO 3080 & $>100$ & Mucor mucedo IFO 5776 & $>100$ \\
\hline Streptococcus faecalis IFO 3181 & $>100$ & Rhizopus oryzae M-21 & $>100$ \\
\hline Pediococcus hennevergi IFO 3884 & $>100$ & Aspergillus oryzae M-61 & $>100$ \\
\hline Leuconostoc mesenteroides IFO 3426 & $>100$ & Penicillium chrysogenum IFO 4626 & $>100$ \\
\hline Lactobacillus plantarum IFO 3070 & $>100$ & Neurospora crassa IFO 6068 & $>100$ \\
\hline Propionibacterium arabinosus IAM 1714 & $>100$ & Fusarium lini IFO 5880 & $>100$ \\
\hline Mycobacterium avium IFO 3154 & $>100$ & Giberella fujikuroi IFO 5268 & $>100$ \\
\hline Nocardia gardneri IFO 3385 & $>100$ & Trichophyton sulfureum IFO 5945 & $>100$ \\
\hline Streptomyces griseus IFO 3430 & 0.8 & & \\
\hline
\end{tabular}

* AKU: Abbreviation for Culture Collection, Faculty of Agriculture, Kyoto University, Kyoto, Japan.

in Table 2. M-81 is primarily active against Gram-positive bacteria. Its activity and spectrum are more limited than those of cryomycin.

The $\mathrm{LD}_{50}$ in mice of $\mathrm{M}-81$ is greater than $300 \mathrm{mg} / \mathrm{kg}$ when given intraperitoneally.

\section{Discussion}

In some respects, on the basis of its properties, M-81 resembles melanomycin ${ }^{3)}$, duramycin ${ }^{4,5)}$ and amphomycin ${ }^{8)}$. However, the nitrogen content and constitutive amino acids of melanomycin differ from those of M-81. Duramycin and amphomycin were isolated from the culture broth by extracting with butanol. Duramycin contains more kinds of amino acids, and amphomycin shows a different infrared absorption spectrum. Hence, M-81 appears to differ from known peptide antibiotics, and is recognized as a new substance. Structural details of M-81 is now being elucidated.

Incidently, it is very unusual for the same strain of microorganism to produce two quite different antibiotics at different temperature ranges. To see if the biosynthesis of M- 81 and cryomycin is related, intact mycelia of $S$. griseus subsp. psychrophilus AKU 2881 were incubated with cryomycin at $28^{\circ} \mathrm{C}$ and with $\mathrm{M}-81$ at $5^{\circ} \mathrm{C}$. Neither the interconversion of the two antibiotics nor the degradation of either was observed ${ }^{11}$. Also, no increase in cryomycin production was observed by shifting the incubation temperature from $28^{\circ} \mathrm{C}$ to $5^{\circ} \mathrm{C}$ during cultivation. Cryomycin production was almost proportional to the mycelia newly developed at low temperature. ${ }^{1}$ Thus, we suppose that cryomycin and M-81 are produced via independent biosynthetic 
routes.

Further discussions on the biosyntheses of M-81 and cryomycin will be made in future when the interrelationships between the chemical structures of the two antibiotics will be revealed.

\section{Acknowledgement}

The authors are indebted to Mr. K. UEDA, Research Institute of Kuraray Co., Ltd., Kurashiki, Japan, for his helpful advices in purification of this antibiotic.

\section{References}

1) Ogata, K.; N. Yoshida, M. Ohsugi \& Y. Tani: Studies on antibiotics produced by psychrophilic microorganisms. I. Production of antibiotics by a psychrophile, Streptomyces sp. No. 81 Agr. Biol. Chem. 35: 79 85, 1971

2) Yoshida, N.; Y. Tani \& K. Ogata: Cryomycin, a new peptide antibiotic produced only at low temperature. J. Antibiotics 25: 653 659, 1972

3) Sugawara, R.; A. Matsumae \& T. Hata: Melanomycin, a new antitumor substance from Streptomyces. J. Antibiotics, Ser. A 10: 133 137, 1957

4) Pridham, T. G.; L. A. Lindenfelser, O. L. Shotwell, F. H. Stodola, C. Foley, R. W. JAckson, W. J. Zaumeyer, W. H. Preston, Jr. \& J.W. Mrtchell: Antibiotics against plant disease. I. Laboratory and green house survey. Phytopathology 46: 568 574, 1956

5) Pridam, T. G.; O. L. Shotwell, F. H. Stodola, L. A. Lindenfelser, R. G. Benedict \& R. W. JACKSON: Antibiotics against plant disease. II. Effective agents produced by Streptomyces cinnamomeus forma azacoluta $\mathrm{F}$ nov. Phytopathology 46: 575 581, 1956

6) Heinemann, B.; M. Y. Kaplan, R.D. Muir \& I. R. Hooper: Amphomycin, a new antibiotic. Antibiot. \& Chemoth. 3: 1239 1242, 1953 